\title{
Late Reperfusion (6-24 Hours After Onset) Improves Left Ventricular Function in Patients With Acute Myocardial Infarction
}

\author{
Shoichi Miyamoto, MD; Yoichi Goto, MD*; Masatoshi Fujita, MD**; \\ Satoshi Daikoku, MD*; Noritoshi Nagaya, MD*; Satoshi Yasuda, MD*; \\ Hitoshi Sumida, MD*; Isao Morii, MD*; Akira Itoh, MD*; \\ Shunichi Miyazaki, MD*; Hiroshi Nonogi, MD*
}

\begin{abstract}
The TAMI- 6 trial has demonstrated that coronary reperfusion $>6 \mathrm{~h}$ after onset (ie, late reperfusion) in patients with acute myocardial infarction (AMI) does not improve left ventricular (LV) function during the chronic phase of infarction. However, the low patency rate (only 60\%) of the infarct-related artery (IRA) during the chronic phase in the TAMI- 6 trial raises a new hypothesis that late reperfusion with a higher patency rate may improve LV function during the chronic phase. Forty-four patients with AMI, who were admitted to hospital 6-24h after the symptom onset and in whom emergency coronary angiography revealed a total occlusion of the IRA, were randomly assigned to either the late reperfusion group $(n=22)$ or the non-reperfusion group $(n=22)$. The initial success rate of reperfusion therapy in the late reperfusion group was $86 \%$ and the chronic patency rate of the IRA was $91 \%$. The improvements in ejection fraction and chord shortening in the infarct region from the acute phase to the chronic phase were significantly greater in the late reperfusion group than in the non-reperfusion group. Late reperfusion with a high patency rate of the IRA significantly improves LV global and regional function in patients with AMI. (Jpn Circ J 2001; 65: 389-394)
\end{abstract}

Key Words: Acute myocardial infarction; Hibernating myocardium; Late reperfusion; Regional wall motion

$\mathbf{R}$ eperfusion of the occluded infarct-related artery (IRA) during the early phase (0-6h) of acute myocardial infarction (AMI) has been shown to reduce infarct size, preserve left ventricular (LV) function, and improve the short- and long-term prognoses ${ }^{1-3}$ Late reperfusion during the relatively late phase (6-24h) of AMI is reported to have a favorable effect on the prevention of LV dilatation and remodeling, but does not have a late benefit on systolic function in a randomized trial. The low patency rate (only 60\%) of the IRA in the chronic phase of the trial may explain the lack of benefit of intravenous thrombolytic therapy on LV function. Primary or rescue percutaneous transluminal coronary angioplasty (PTCA) has successfully increased the patency rate both during the acute and chronic phases of infarction ${ }^{5-7}$ Therefore, we hypothesized that late reperfusion with a high patency rate would improve hibernating LV function.

Thus, a prospective, randomized, controlled trial was designed to evaluate whether intracoronary thrombolysis and/or PTCA during the relatively late phase of AMI is effective in preserving LV function.

(Received December 6, 2000; revised manuscript received February 5, 2001; accepted February 13, 2001)

Division of Cardiology, Takeda Hospital, Kyoto, *Division of Cardiology, National Cardiovascular Center, Osaka and **College of Medical Technology, Kyoto University, Kyoto, Japan

Mailing address: Professor Masatoshi Fujita, MD, College of Medical Technology, Kyoto University, 53 Kawaharacho, Shogoin, Sakyo-ku, Kyoto 606-8507, Japan. E-mail: mfujita@kuhp.kyoto-u.ac.jp

\section{Methods}

\section{Patient Population}

Between May 1990 and September 1996, 44 patients with AMI of more than $6 \mathrm{~h}$ but less than $24 \mathrm{~h}$ after the onset of symptoms were considered for entry into the study. There were 34 men and 10 women with a mean age of 61 years (range, 39-80 years).

\section{Treatment Protocol}

After the attending physician obtained their informed consent, patients were randomly assigned to either the nonreperfusion group $(n=22)$ or the late reperfusion group $(n=22)$ using the envelope method. All patients were intravenously administered 5,000 $\mathrm{U}$ of heparin and transported promptly to the catheterization laboratory. A second 5,000 U bolus of heparin was administered intravenously after femoral access was obtained. Coronary angiography was first performed on the non-IRA to evaluate the extent of the collateral circulation to the area perfused by the completely occluded IRA. In the non-reperfusion group no intervention was applied. However, in the late reperfusion group, intracoronary thrombolysis (ICT) and/or PTCA was performed. Tissue-type plasminogen activator $(n=17)$ was administered into the IRA through a selective coronary catheter at a rate of $160,000 \mathrm{U} / \mathrm{min}$ with a maxium dose of $6,400,000 \mathrm{U}$. Eleven patients with unsuccessful thrombolysis and with a Thrombolysis in Myocardial Infarction (TIMI) flow grade of 0 to 2 underwent rescue coronary angioplasty. Either primary $(n=5)$ or rescue $(n=11)$ PTCA was performed in a routine manner with the use of appropriately sized angioplasty balloon catheters. Repeated balloon infla- 
tions were performed in an attempt to decrease the residual stenosis to $\leq 50 \%$. The procedure's success was defined as achieving a flow of TIMI grade 3 at the time of the patient's discharge from the catheterization laboratory. A continuous intravenous infusion of heparin and nitroglycerin was given for 24-72 $\mathrm{h}$ after the procedure.

\section{Clinical Variables}

The presence or absence of a history of pre-infarction angina before the onset of AMI was documented. Preinfarction, long-standing stable angina was defined as typical anginal chest pain occurring $>1$ week before the onset of AMI8 Pre-infarction unstable angina was defined as typical anginal chest pain occurring $\leq 1$ week before the onset of AMI. A history of hypertension was defined as a systolic pressure $\geq 160 \mathrm{mmHg}$, a diastolic pressure $\geq 95$ $\mathrm{mmHg}$ or when currently undergoing treatment for hypertension. The diagnosis of diabetes mellitus was established based on any one of the following 3 factors: (i) history of taking insulin or an oral hypoglycemic agent; (ii) abnormal pre-infarction fasting glucose levels $(\geq 120 \mathrm{mg} / 100 \mathrm{ml})$; or (iii) positive results on a $75 \mathrm{~g}$ oral glucose tolerance test.

\section{Coronary Angiographic and Procedural Characteristics}

The IRA, the severity of coronary artery disease, and the extent of residual stenosis and collateral circulation were determined with coronary angiography at the onset of AMI. We also documented complications related to the ICT or PTCA procedure, such as bleeding, coronary dissection or hemodynamic instability requiring the use of intra-aortic balloon pumping.

Follow-up coronary angiography was conducted using the Judkins technique in 44 patients 29 days (range 2335 days) after the onset of AMI. Quantitative analysis of the percent lumen diameter stenosis of the IRA was performed using a caliper on adequately magnified, $35 \mathrm{~mm}$ cine frames from the end-diastolic phase in multiple projections. The projection showing the most severely narrowed coronary was selected.

\section{Analysis of Ventriculograms}

Left ventriculography was performed using a power injection with the patient in the $30^{\circ}$ right anterior oblique position. The endocardial contours of the left ventricle at the end-diastolic and end-systolic frames of the left ventriculograms, which were obtained about 1 month (29 \pm 6 days) after the symptom onset of AMI, were traced independently by 3 different observers. In all 44 patients, left ventriculography was also performed before the completion of reperfusion therapy and was analyzed following the procedure used during the chronic phase. Left ventricular volume was calculated by the area-length $\operatorname{method}^{9}$ and used to determine the ejection fraction. ${ }^{10}$ Regional wall motion was calculated by the centerline method 11 A computer generated the centerline between the systolic and diastolic contours, and 100 equally spaced chords were drawn perpendicular to the centerline. Chord 1 was drawn at the intersection of the aortic contour and the anterobasal LV wall, and chord 100 was drawn at the junction of the LV contour and the posterior aortic contour.

The measured motion of each chord was normalized for heart size by dividing it by the length of the end-diastolic perimeter and then expressed in terms of standard deviation units (SD) above or below the normal mean motion of chords. Normal chord motion in the laboratory was derived from the ventriculograms of 50 patients with normal LV function without coronary artery or valvular heart disease.

Abnormalities in wall motion were calculated by 2 approaches. First, the severity of hypokinesis in the infarct region was calculated as the mean of the chord lying in the hypokinetic area and expressed as the SD per chord. Second, the circumferential extent of hypokinesis was also calculated as the set of contiguous chords whose motion was depressed more than \pm 2 SD below the normal mean and expressed as a percentage of the endocardial contour length.

\section{Measurement of Creatine Kinase Activity}

Blood samples for the measurement of creatine kinase activity were drawn every $3 \mathrm{~h}$ for the first $24 \mathrm{~h}$ and every $6 \mathrm{~h}$ for the next $24 \mathrm{~h}$ of AMI. Serum creatine kinase activity was determined spectrophotometrically using Rosalki's method! 12

\section{Collateral Circulation}

Collateral circulation was graded on a scale of $0-3$, depending on the degree of opacification of the occluded vessel. The score of the collateral index was based on the injection that best opacified the occluded vessel: 0 , no opacification; 1 , filling of side branches of the artery to be perfused by way of the collateral vessels without visualization of the epicardial segment; 2, partial filling of the epicardial segment by way of the collateral vessels; and 3 , complete filling of the epicardial segment by way of the collateral vessels ${ }^{3}$ Three blinded observers assessed the coronary cineangiograms and reached a consensus.

\section{Clinical Follow Up}

During the in-hospital convalescent period, $80 \mathrm{mg}$ of aspirin, taken orally, was administered daily. Oral calcium channel antagonists, nitrates, angiotensin-converting enzyme inhibitors and $\beta$-adrenergic blocking agents were given at the discretion of the attending physician, in which nitrates were administered to $59 \%$ of patients in the non-reperfusion group compared to $64 \%$ in the late reperfusion group $(\mathrm{p}=$ NS), calcium channel antagonists were administered to $59 \%$ vs $45 \%(\mathrm{p}=\mathrm{NS})$, angiotensin-converting enzyme inhibitors were administered to $27 \%$ vs $18 \%(\mathrm{p}=\mathrm{NS}$ ) and $\beta$-adrenergic blocking agents were administered to $5 \%$ vs $9 \%(\mathrm{p}=\mathrm{NS})$. There were no significant differences between the 2 groups. No patients received angiotensin II blockers during the study.

\section{Statistical Analysis}

Values are expressed as the mean \pm SD (SE). Comparisons of variables between 2 groups were determined by Fisher's exact test or unpaired Student's t-test. Values were considered significant at $\mathrm{p}<0.05$.

\section{Results}

\section{Patient Population}

The clinical characteristics of the 44 patients with followup angiography are summarized in Table 1 . The 2 groups were well balanced with respect to all cardiovascular risk factors and family history. Neither the incidence of stable pre-infarction angina nor unstable pre-infarction angina significantly differed between the 2 groups. During the mean follow-up period of $29 \pm 6$ days, clinical events including recurrent ischemia, re-infarction, death from any cause, and treatment with repeated coronary angioplasty or 
Table 1 Clinical Characteristics of the 44 Patients Randomly Assigned to Non-Reperfusion or Late Reperfusion Therapy

\begin{tabular}{lccc}
\hline \hline & $\begin{array}{c}\text { Non-reperfusion } \\
(n=22)\end{array}$ & $\begin{array}{c}\text { Late reperfusion } \\
(n=22)\end{array}$ & $p$ value \\
\hline Age (years) & $62 \pm 9$ & $59 \pm 9$ & $N S$ \\
Male & $15(68 \%)$ & $19(86 \%)$ & $N S$ \\
Preinfarction stable angina & $10(45 \%)$ & $11(50 \%)$ & $N S$ \\
Preinfartion unstable angina & $9(41 \%)$ & $10(45 \%)$ & $N S$ \\
Hypertension & $13(59 \%)$ & $10(45 \%)$ & $N S$ \\
Diabetes mellitus & $6(27 \%)$ & $7(32 \%)$ & $N S$ \\
Cigarette smoking & $12(55 \%)$ & $14(64 \%)$ & $N S$ \\
Hyperlipidemia & $6(27 \%)$ & $5(23 \%)$ & $N S$ \\
Obesity (BMI $\geq 26.4)$ & $9(41 \%)$ & $8(36 \%)$ & $N S$ \\
Family history & $7(32 \%)$ & $2(9 \%)$ & $N S$ \\
\hline
\end{tabular}

Values are presented as the number (\%) of patients or mean value $\pm S D$. BMI, body mass index.

Table 2 Angiographic Findings

\begin{tabular}{|c|c|c|c|}
\hline & $\begin{array}{c}\text { Non-reperfusion } \\
(n=22)\end{array}$ & $\begin{array}{l}\text { Late reperfusion } \\
\quad(n=22)\end{array}$ & $p$ value \\
\hline \multicolumn{4}{|l|}{ Infarct-related vessel (\%) } \\
\hline$L A D$ & 59 & 36 & $N S$ \\
\hline$L C x$ & 9 & 18 & \\
\hline$R C A$ & 32 & 46 & \\
\hline Recanalization rate: acute phase $(=$ TIMI $3, \%)$ & 0 & 86 & $<0.01$ \\
\hline \multicolumn{4}{|l|}{ No. of diseased vessels: acute phase (\%) } \\
\hline 1 & 71 & 50 & $N S$ \\
\hline 2 & 10 & 35 & \\
\hline 3 & 19 & 15 & \\
\hline \multicolumn{4}{|l|}{ Collateral circulation (\%) } \\
\hline None & 14 & 23 & $N S$ \\
\hline Poor & 36 & 23 & \\
\hline Fair & 41 & 41 & \\
\hline Good & 9 & 13 & \\
\hline Patency (IRA): chronic phase (= TIMI 3, \%) & 41 & 91 & $<0.01$ \\
\hline
\end{tabular}

LAD, left anterior descending coronary artery; LCx, left circumflex artery; RCA, right coronary artery; TIMI, Thrombolysis in Myocardial Infarction; IRA, infarct-related artery.

bypass grafting, did not occur in any of the 44 patients.

\section{Angiographic Features}

There were no differences between the 2 groups regarding the distribution of IRA, severity of coronary artery disease, and extent of collateral circulation. In the acute phase of infarction, the recanalization rate with TIMI flow grade 3 was $86 \%$ in the late reperfusion group; however, all patients in the non-reperfusion group had less than TIMI flow grade 2. During the chronic phase, the patency rate with TIMI flow grade 3 was $41 \%$ and $91 \%$ in the nonreperfusion and late reperfusion groups, respectively $(p<0.01$; Table 2; Fig 1). The initial success rate of the late reperfusion group (86\%) and the chronic patency rate of the IRA (91\%) in the present study were significantly higher than those reported in the TAMI- 6 triall

\section{Hemodynamics}

The heart rate was lower during the chronic phase compared to during the acute phase (non-reperfusion group, $71 \pm 13$ beats $/ \mathrm{min}$ compared with $80 \pm 11$ beats $/ \mathrm{min}$; late reperfusion group, $70 \pm 11$ beats/min compared with $79 \pm 12$ beats $/ \mathrm{min}, \mathrm{p}<0.05$, respectively). No significant changes in the LV peak systolic pressure were observed between the acute and chronic phases in the 2 groups. In the late reperfusion group, the LV end-diastolic pressure decreased significantly from $16 \pm 7 \mathrm{mmHg}$ during the acute phase to $11 \pm 5 \mathrm{mmHg}$ during the chronic phase. In the non-reperfu-

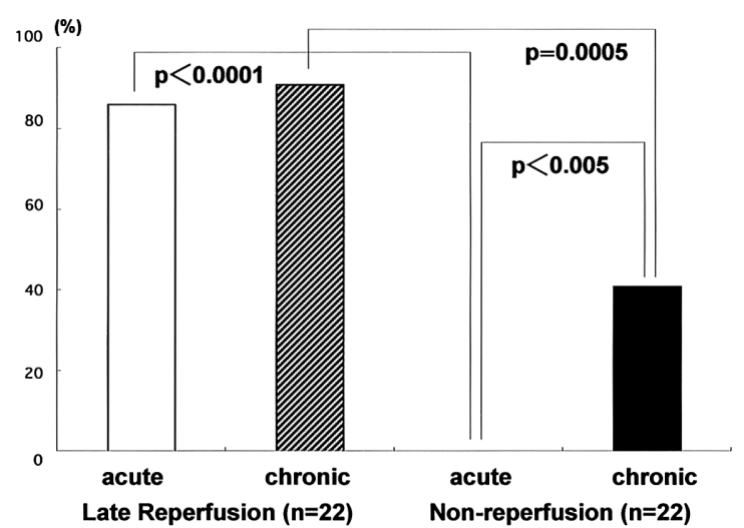

Fig 1. The initial success rate (86\%) and the chronic patency rate of the infarct-related artery (IRA) $(91 \%)$ in the late reperfusion group were significantly higher than the initial successful rate $(0 \%)$ and the chronic patency rate of the IRA $(41 \%)$ in the non-reperfusion group.

sion group, the differences in LV end-diastolic pressure between the acute and chronic phases were not significant (Table 3).

\section{Overall Left Ventricular Function}

In the late reperfusion group, the cardiac index increased during the convalescent period from $2.5 \pm 0.4$ to $3.1 \pm 0.8$ 
Table 3 Hemodynamics and Left Ventricular Function

\begin{tabular}{|c|c|c|}
\hline & $\begin{array}{c}\text { Non-reperfusion } \\
(n=22)\end{array}$ & $\begin{array}{l}\text { Late reperfusion } \\
(n=22)\end{array}$ \\
\hline \multicolumn{3}{|c|}{$H R$ (beats/min) } \\
\hline Acute & $80 \pm 11$ & $79 \pm 12$ \\
\hline Chronic & $71 \pm 13^{*}$ & $70 \pm 11 *$ \\
\hline \multicolumn{3}{|c|}{ LVPSP (mmHg) } \\
\hline Acute & $122 \pm 18$ & $122 \pm 19$ \\
\hline Chronic & $117 \pm 22$ & $118 \pm 21$ \\
\hline \multicolumn{3}{|c|}{$L V E D P(m m H g)$} \\
\hline Acute & $15 \pm 6$ & $16 \pm 7$ \\
\hline Chronic & $15 \pm 7$ & $11 \pm 5 *$ \\
\hline \multicolumn{3}{|c|}{$C I\left(L \cdot \mathrm{min}^{-1} \cdot m^{2}\right)$} \\
\hline Acute & $2.6 \pm 0.6(n=12)$ & $2.5 \pm 0.4(n=9)$ \\
\hline Chronic & $2.4 \pm 0.6(n=12)$ & $3.1 \pm 0.8(n=9) * \dagger$ \\
\hline \multicolumn{3}{|c|}{$\operatorname{LVEDVI}\left(\mathrm{ml} / \mathrm{m}^{2}\right)$} \\
\hline Acute & $67 \pm 12$ & $72 \pm 16$ \\
\hline Chronic & $72 \pm 16^{*}$ & $73 \pm 13$ \\
\hline \multicolumn{3}{|c|}{$\operatorname{LVESVI}\left(\mathrm{ml} / \mathrm{m}^{2}\right)$} \\
\hline Acute & $37 \pm 10$ & $38 \pm 10$ \\
\hline Chronic & $40 \pm 14$ & $36 \pm 11$ \\
\hline \multicolumn{3}{|l|}{$E F(\%)$} \\
\hline Acute & $46 \pm 8$ & $48 \pm 9$ \\
\hline Chronic & $45 \pm 9$ & $51 \pm 9 * \dot{*}$ \\
\hline \multicolumn{3}{|l|}{$C S_{I R}(\%)$} \\
\hline Acute & $0.87 \pm 0.84$ & $0.98 \pm 0.85$ \\
\hline Chronic & $1.06 \pm 1.16$ & $1.82 \pm 1.06^{* \dagger}$ \\
\hline
\end{tabular}

Values are mean $\pm S D$. HR, heart rate; LVPSP, left ventricular peak systolic pressure; LVEDP, left ventricular end-diastolic pressure; CI, cardiac index; LVEDVI, left ventricular end-diastolic volume index; LVESVI, left ventricular end-systolic volume index; $E F$, ejection fraction; CSIR, chord shortening in the infarct region. ${ }^{*} p<0.05$ vs acute phase, ${ }^{\dagger} p<0.05 v$ Non-reperfusion group.

A

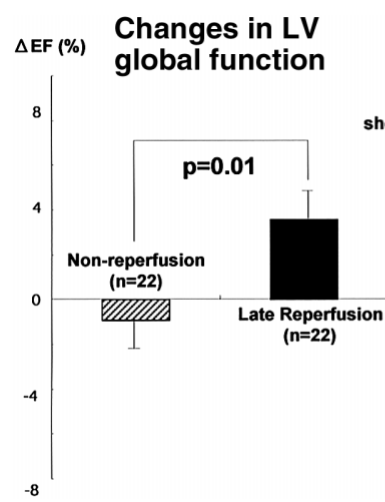

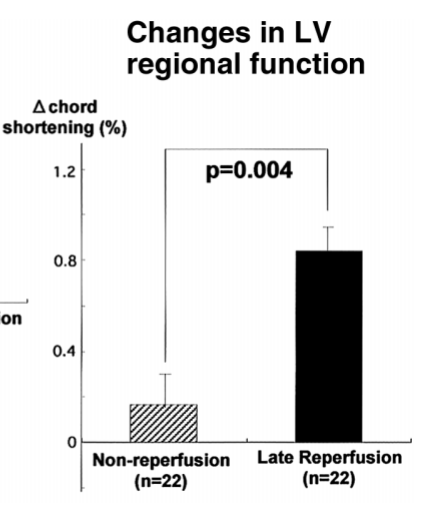

B

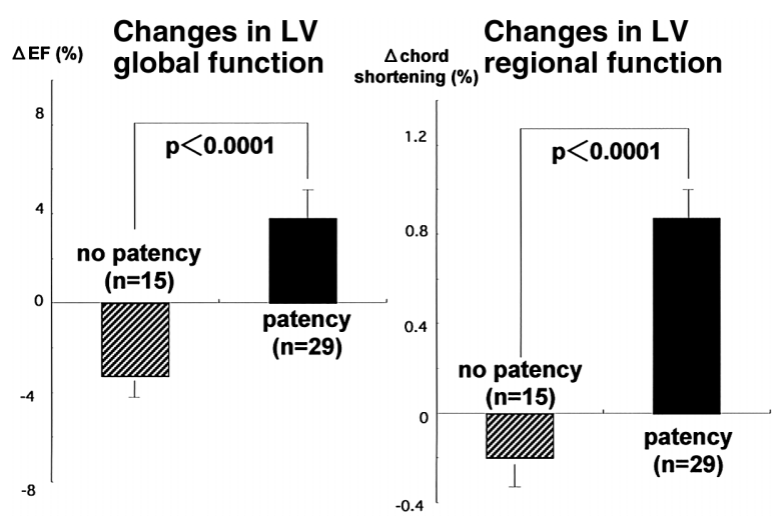

Fig2. (A) The extent of improvement in ejection fraction (EF) from the acute phase to the chronic phase was significantly greater in the late reperfusion group compared to the non-reperfusion group. The extent of improvement in chord shortening in the infarct region (CSIR) was significantly greater in the late reperfusion group than in the non-reperfusion group. Values are mean \pm SE. (B) The extent of improvement in EF from the acute phase to the chronic phase was significantly greater in the patency group during the chronic phase compared to the no patency group during the chronic phase. The extent of improvement in CSIR was significantly greater in the patency group during the chronic phase than in the no patency group during the chronic phase. Values are mean $\pm \mathrm{SE}$.

$\mathrm{L} \cdot \min ^{-1} \cdot \mathrm{m}^{2}$. There was a significant increase in end-diastolic volume index for the non-reperfusion group between the acute and chronic phase and no significant diastolic cavity size increase in the late reperfusion group. The global ejection fraction (EF) during the acute phase was $46 \pm 8 \%$ and $48 \pm 9 \%$ in the non-reperfusion and late reperfusion groups, respectively (NS); during the chronic phase, it was $45 \pm 9 \%$ and $51 \pm 9 \%$, respectively $(\mathrm{p}<0.05)$. The extent of improvement in $\mathrm{EF}$ from the acute phase to the chronic phase was significantly greater in the late reperfusion group than in the non-reperfusion group $(-0.9 \pm 1.3 \%$ vs $3.6 \pm 1.1 \%$, $\mathrm{p}<0.05$; Fig $2 \mathrm{~A}$ ). Thus, the global EF was significantly augmented only in the late reperfusion group (Table 3 ).

\section{Regional Myocardial Function}

The chord shortening in the infarct area during the acute phase was $0.87 \pm 0.84 \%$ and $0.98 \pm 0.85 \%$ in the non-reperfusion and late reperfusion groups, respectively (NS). During the chronic stage, the chord shortening was $1.06 \pm 1.16 \%$ and $1.82 \pm 1.06 \%$ in the non-reperfusion and late reperfusion groups, respectively $(\mathrm{p}<0.05)$. Patients in the late reperfusion group showed a significant improvement $(p<0.05)$ in chord shortening. The extent of improvement in chord shortening in the infarct region (CSIR) was significantly 
Table 4 Peak Creatine Kinase (CK) Level

\begin{tabular}{lccc}
\hline \hline & $\begin{array}{c}\text { Non-reperfusion } \\
(n=22)\end{array}$ & $\begin{array}{c}\text { Late reperfusion } \\
(n=22)\end{array}$ & p value \\
\hline Peak CK level $(U / L)$ & $2,999 \pm 1,314$ & $3,094 \pm 2,034$ & $N S$ \\
Time to peak $C K$ level $(h)$ & $27 \pm 6$ & $20 \pm 5$ & $<0.01$ \\
Time until reperfusion $(h)$ & & $12 \pm 3$ & \\
\hline
\end{tabular}

Values are mean $\pm S D$.

greater in the late reperfusion group compared to the nonreperfusion group $(0.84 \pm 0.13 \%$ vs $0.17 \pm 0.18 \%, \mathrm{p}<0.01$; Fig 2A). In the non-reperfusion and late reperfusion groups, the differences in the extent of reduced wall motion were not significant between the acute and chronic phases.

Despite similar infarct sizes, functional recovery was observed only in the late reperfusion group. Indeed, in patients with a patent IRA during the chronic stage, LV wall motion was well maintained compared with those with an occluded IRA (Fig 2B). Of those in the late reperfusion group, 2 patients did not have TIMI 3 flow during the acute and chronic phases. For these 2 patients, the functional recovery (global and regional myocardial function) was not significantly different from the non-reperfusion group $(-3.0 \pm$ $1.0 \%$ vs $-0.9 \pm 1.3 \%, \mathrm{p}=\mathrm{NS}$ and $0.54 \pm 0.04 \%$ vs $0.17 \pm 0.18 \%$, $\mathrm{p}=\mathrm{NS}$ ).

\section{Comparison of Timing During Late Reperfusion}

Among the patients in the late reperfusion group, the improvements in EF and chord shortening in the infarct area were similar between patients with late reperfusion at $6-12 \mathrm{~h}$ and those with late reperfusion at $12-24 \mathrm{~h}$.

\section{Creatine Kinase}

The peak serum creatine kinase level for each group is shown in Table 4. There were no significant differences in the peak serum creatine kinase levels between the nonreperfusion group $(2,999 \pm 1,314 \mathrm{U} / \mathrm{L})$ and the late reperfusion group $(3,094 \pm 2,034 \mathrm{U} / \mathrm{L})$. The time to peak creatine kinase level was significantly shorter in the late reperfusion group compared to the non-reperfusion group $(20 \pm 5 \mathrm{~h}$ vs $27 \pm 6 \mathrm{~h}, \mathrm{p}<0.01$ ), presumably due to the high recanalization rate of the IRA in the late reperfusion group.

\section{Discussion}

The present findings demonstrated that late reperfusion (6-24 h after the onset of AMI) for an occluded IRA provides a high initial success rate and a low re-occlusion rate, and has a beneficial effect on LV functional recovery compared with persistent occlusion of the IRA.

\section{Comparison With Previous Studies}

With regard to the prevention of LV remodelling after AMI, the favorable effect of late reperfusion in the present study was similar to earlier studies $4,14,15$ However, only in the present study, was a significant recovery in LV function observed. This was mainly due to the higher patency rate $(91 \%)$ of the IRA in the present study. In contrast, it was $32 \%$ in the study by Hirayama et al, and $60 \%$ in the TAMI6 study.,14 Alternatively, a higher rate (54\%) of well-developed collateral circulation ( $\geq$ grade 2 ) during the acute stage for patients in the present series with late reperfusion may explain the significant functional recovery! 16,17 The frequency of the presence of well-developed collaterals was only $16 \%$ in the study by Hirayama et al ${ }^{14}$

\section{Hibernating Myocardium}

It is likely that the extent of improvement of wall motion in the infarct area after revascularization depends on the amount of viable but dysfunctional myocardium (hibernating myocardium). Because there was a significant functional recovery in the patients in the present series with late reperfusion, this suggests the presence of a sizable amount of hibernating myocardium in these patients. This may have been accomplished by functionally significant, pre-existent collateral circulation toward the infarct zone. Indeed, a high frequency (54\%) of angiographically visible collaterals in patients in the present series explains favorably the aforementioned assumption. Although in the present study the IRA was reperfused 6-24h following the onset of AMI, Sabia et al reported that PTCA, which was performed during the convalescent period of infarction, caused a significant functional recovery if contrast echocardiography visualized the collateral circulation to the infarct zone! 8 These findings suggest that assessing myocardial viability is useful!9-21 Therefore, the reperfusion of the IRA should be attempted during any stage of infarction when a sizable amount of hibernating myocardium exists.

\section{Study Limitations}

There are several limitations inherent to the present study. First, the location of myocardial infarction largely affects LV global and regional function ${ }^{14}$ Accordingly, it is desirable that the infarct sites are similar for all patients. Patients included in the present series had AMI at various sites, which may make it difficult to compare functional improvement between the 2 groups. However, the distribution of the infarct site was comparable between the 2 groups. Thus, it is likely that late reperfusion contributed to the amelioration of LV functional in the present study.

Second, we could not reveal the beneficial effect of late reperfusion on the prognosis. This is due, at least in part, to the small number of patients enrolled in the study and the good prognosis for patients without late reperfusion.

Third, successful thrombolytic reperfusion was obtained in 6 of 22 patients with late reperfusion, and successful PTCA recanalization was obtained in 13 patients. This may make interpreting late reperfusion difficult. In this regard, future studies are necessary to clarify which method of reperfusion is limited to primary PTCA.

Fourth, the presence or absence of ischemic preconditioning may influence LV functional recovery ${ }^{22-24}$ However, it is well known that the beneficial effect of the ischemic precondition is limited in patients undergoing early reperfusion within $6 \mathrm{~h}$ after the onset of AMI. Therefore, it is unlikely that the present findings were influenced by the presence or absence of pre-infarction unstable angina.

Finally, well-developed pre-existent collaterals may contribute to improvements in LV function even without 
reperfusion 25 Frequency of patients with fair and good collateral circulation was comparable $(50 \%$ in the nonreperfusion group compared with $54 \%$ in the late reperfusion group) between the 2 groups. Thus, the effect of collaterals on LV function was reasonably excluded in the present study.

\section{Conclusion}

During the chronic stage of AMI, LV global and regional wall motion was well preserved in patients with late reperfusion therapy, presumably due to the high patency rate of the IRA. In contrast, for patients with a permanently occluded IRA, LV global and regional wall motion remained depressed because of the existence of hibernating myocardium.

\section{References}

1. Simoons ML, Serruys PW, van den rand M, Res J, Verheugt FW, Krauss XH, et al: Early thrombolysis in acute myocardial infarction: Limitation of infarct size and improved survival. J Am Coll Cardiol 1986; 7: 717-728

2. National Heart Foundation of Australia Coronary Thrombolysis Group: Coronary thrombolysis and myocardial salvage by tissue plasminogen activator given up to $4 \mathrm{~h}$ after onset of myocardial infarction. Lancet 1988; 1: 203-208

3. Van der Werf F, Arnold AE: Intravenous tissue plasminogen activator and size of infarct, left ventricular function, and survival in acute myocardial infarction. Br Med J 1988; 297: 1374-1379

4. Topol EJ, Califf RM, Vandormael M, Grines CL, George BS, Sanz ML, et al: A randomized trial of late reperfusion therapy for acute myocardial infarction. Circulation 1992; 85: 2090-2099

5. Zeymer U, Neuhaus KL: Thrombolysis and percutaneous transluminal coronary angioplasty in patients with acute myocardial infarction. $Z$ Kardiol 2000; 89(Suppl 4): IV30-IV40

6. Vogt A, Neuhaus KL: Therapy of acute myocardial infarct: Primary PTCA or thrombolysis? Herz 1999; 24: 363-368

7. Bar FW, Ophnis TJ, Frederiks J, de Swart HB, van Ommen VG, de Zwaan C, et al: Rescue PTCA following failed thrombolysis and primary PTCA: A retrospective study of angiographic and clinical outcome. J Thromb Thrombolysis 1997; 4: 281-288

8. Fujita M, Sasayama S, Ohno A, Nakajima H, Asanoi H: Importance of angina for development of collateral circulation. Br Heart J 1987; 57: $139-143$

9. Kennedy JW, Trenholme SE, Kasser IS: Left ventricular volume and mass from single plane angiogram: A comparison of anteroposterior and right anterior oblique methods. Am Heart J 1970; 80: 343-352

10. Dodge HT, Sandler H, Baxley WA, Hawley RR: Usefulness and limitation of radiographic methods for determining left ventricular volume. Am J Cardiol 1966; 18: 10-24

11. Sheehan FH, Bolson EL, Dodge HT, Mathey DG, Schofer J, Woo
HW: Advantages and applications of the centerline method for characterizing regional ventricular function. Circulation 1986; 74: 293-305

12. Rosalki SB: An improved procedure for serum creatine phosphokinase determination. J Lab Clin Med 1967; 69: 696-705

13. Rentrop KP, Cohen M, Blanke H, Phillips RA: Changes in collateral channel filling immediately after controlled coronary artery occlusion by an angioplasty balloon in human subjects. J Am Coll Cardiol 1985; 5: $587-592$

14. Hirayama A, Adachi T, Asada S, Mishima M, Nanto S, Kusuoka H, et al: Late reperfusion for acute myocardial infarction limits the dilatation of left ventricle without the reduction of infarct size. Circulation 1993; 88: 2565-2574

15. Horie H, Takahashi M, Minai K, Izumi M, Takaoka A, Nozawa M, et al: Long-term beneficial effect of late reperfusion for acute anterior myocardial infarction with percutaneous transluminal angioplasty. Circulation 1998; 98: 2377-2382

16. Rogers WJ, Hood Jr WP, Mantle JA, Baxley WA, Kirklin JK, Zorn GL, et al: Return of left ventricular function after reperfusion in patients with myocardial infarction: Importance of subtotal stenoses or intact collaterals. Circulation 1984; 69: 338-349

17. Saito Y, Yasuno M, Ishida M, Suzuki K, Matoba Y, Emura M, et al: Importance of coronary collaterals for restoration of left ventricular function after intracoronary thrombolysis. Am J Cardiol 1985; 55: $1259-1263$

18. Sabia PJ, Powers ER, Jayaweera AR, Ragosta M, Kaul S: Functional significance of collateral blood flow in patients with recent acute myocardial infarction: A study using myocardial contrast echocardiography. Circulation 1992; 85: 2080-2089

19. Bonow RO, Dilsizian V, Cuocolo A, Bacharach SL: Identification of viable myocardium in patients with chronic coronary artery disease and left ventricular dysfunction: Comparison of thallium scintigraphy with reinjection and PET imaging with $18 \mathrm{~F}$-fluorodeoxyglucose. Circulation 1991; 83: 26-37

20. Tillisch J, Brunken R, Marshall R, Schwaiger M, Mandelkern M, Phelps M, et al: Reversibility of cardiac wall motion abnormalities predicted by positron tomography. $N$ Engl J Med 1986; 314: 884-888

21. La Canna G, Alfieri O, Giubbini R, Gargano M, Ferrari R, Visioli O: Echocardiography during infusion of dobutamine for identification of reversible dysfunction in patients with chronic coronary artery disease. J Am Coll Cadiol 1994; 23: 617-626

22. Hirai T, Fujita M, Yoshida N, Yamanishi K, Inoko M, Miwa K: Importance of ischemic preconditioning and collateral circulation for left ventricular functional recovery in patients with successful intracoronary thrombolysis for acute myocardial infarction. Am Heart $J$ 1993; 126: 827-831

23. Kloner RA, Yellon D: Does ischemic preconditioning occur in patients? J Am Coll Cardiol 1994; 24: 1133-1142

24. Nakagawa Y, Ito H, Kitakaze M, Kusuoka H, Hori M, Kuzuya T, et al: Effect of angina pectoris on myocardial protection in patients with reperfused anterior wall myocardial infarction: Retrospective clinical evidence of 'Preconditioning'. J Am Coll Cardiol 1995; 25: $1076-1083$

25. Hirai T, Fujita M, Nakajima H, Asanoi H, Yamanishi K, Ohno A, et al: Importance of collateral circulation for prevention of left ventricular aneurysm formation in acute myocardial infarction. Circulation 1989; 79: 791-796 